\title{
Body image is an important augmentation to quality of life in evaluating the results of laparoscopic versus classic surgery
}

\author{
Tomasz J. Stefaniak ${ }^{1,2,3}$, Katarzyna Adamczyk², Anna Walerzak², Derek Gill2, Ad Vingerhoets ${ }^{4}$, tukasz Kaska', \\ Wojciech Makarewicz' ${ }^{1}$, Zbigniew Gruca ${ }^{1}$, Andrzej J. Łachiński ${ }^{1}$, Zbigniew Śledziński ${ }^{1}$ \\ 1Department of General, Endocrine and Transplant Surgery, Medical University of Gdansk, Poland \\ 2Laboratory of Psychology of Surgery and Psychosomatics, Department of General, Endocrine and Transplant Surgery, Medical University \\ of Gdansk, Poland \\ ${ }^{3}$ Pomeranian Fundation for Progress in Surgery, Gdansk, Poland \\ 4Department of Clinical Psychology, Tilburg University, The Netherlands
}

Videosurgery and other miniinvasive techniques 2010; 5 (4): 146-151 DOI: 10.5114 /wiitm.2010.18828

\begin{abstract}
Introduction: Apart from the positive biomedical consequences, there are supposed psychological benefits gained by patients due to laparoscopy. To evaluate the psychological consequences of surgical intervention areas such as the quality of a patient's life and subjective body image perception are explored.

Aim: The purpose was to determine the value of body esteem evaluation in differentiation of the results of laparoscopic vs. classic surgery in the context of insufficient sensitivity of quality of life measures in such differentiation.

Material and methods: There were 57 participants treated with laparoscopic and classic cholecystectomies and adrenalectomies in the Department of Surgery, Medical University of Gdansk, Poland. Two types of psychological measures were used: the Body Esteem Scale (BES) and Functional Assessment of Chronic Illness Therapy (FACIT). Both surveys were distributed to the patients 1 day before and 1 month after the operation.

Results: One month after the intervention, QoL, according to FACIT, increased slightly among patients after both laparoscopic and classic surgery (respectively 4.5\% and 6.8\%, $p<0.005$ ), while the body image indicator decreased by $2.9 \%$ after the laparoscopic operation, compared to $28.5 \%$ after classic surgery. Multiple logistic regression revealed that high body esteem scale results were significant predictors of the laparoscopic approach (OR 2.15, $95 \% \mathrm{Cl}$ 2.01-2.86) while quality of life alone was not a significant differentiator of the approaches used (OR 1.01,95\% CI 0.75-1.35).

Conclusions: Body image studies provide more sensitive information capable of distinguishing between laparoscopic and classic approaches than merely quality of life measures, which justifies the complementary use of BI in the comparative assessment of classic and laparoscopic surgery.
\end{abstract}

Key words: laparoscopy, surgery, quality of life, body image, methodology

\section{Introduction}

Surgical operations have been performed since the times of the ancients. At the turn of the $20^{\text {th }}$ century all organs, including the brain, were operated on using medical sharps. Surgical interventions per- formed in the classical method have always left a scar. At the end of the $20^{\text {th }}$ century there was a breakthrough: the invention of the laparoscopic method. This has created a whole new attitude toward scars. Since then, big operations no longer demand large incisions. Because of this, an innova- 
tive specialization was developed: surgical procedures which leave no visible marks.

The undeniable advantages of laparoscopic interventions are shorter treatment time, including shorter convalescence and better wound healing, better cosmetic effect due to smaller cuts, small invasion and tissue trauma, maintaining the continuity of the skin, and statistically lower numbers of complications [1-5].

Apart from the positive biomedical consequences, there are supposed psychological benefits the patients gain due to laparoscopy. Aside from medical measures, there are also psychological methods used by scientists to evaluate the psychological consequences of surgical intervention in areas such as the quality of a patient's life. Quality of life (QoL) is one of the most common psychological measures used in surgery. In the PubMed database, which is a part of the U.S. National Library of Medicine and the National Institutes of Health, there are over 30 thousand articles addressing the subject of life quality and surgery. It has also been widely used in evaluation of the results of different laparoscopic and open operations, including general, endocrine and subspecialty surgery, such as bariatric [6-9]. Thus, the most intuitive way of evaluating the effects of treatment should be by assessing the quality of life. It is widely believed that the postoperative quality of life should be at least at the same level as prior to surgery. It is also tempting to use quality of life as a measure of the advantages of the minimally invasive approach. In a study of Velanovich et al. [6] assessing the quality of life of patients undergoing 4 different types of laparoscopic and open operations - elective inguinal hernioplasty, oesophageal surgery, cholecystectomy, and splenectomy - patients completed the SF-36, a quality of life instrument. The minimally invasive approach was superior to the open method in all aspects of quality of life, but only in a short perspective ( 2 weeks postoperatively). Similar results have been observed by the authors of the COST study, who proved that quality of life differentiated the 2 mentioned approaches only within the first 2 weeks after surgery [10]. In a meta-analysis conducted by Keus et al., the long-term results of cholecystectomy with open and laparoscopic approaches were not different in terms of quality of life despite the fact that the morbidity was significantly higher in the open group [11]. Nevertheless, in some cases, quality of life measures are used in an inadequate way, creating important biases that may influence the conclusions of the entire work. Self-constructed, non-validated, so-called quality of life scales may serve as the best example. The reliability of such a scale and its methodologically uncertain interpretation leave much to be desired.

The simplicity of using the quality of life scale makes it tempting for overuse and inadequate interpretation. Quality of life sometimes seems to be just another tool of measurement for the surgeon, almost like haemoglobin levels in the blood.

On the other hand, the success of minimally invasive surgery seems to be more definitive than could just appear from short-term improvement of quality of life. One of the well known psychological methods, also appearing adequate in this case, is subjective body image perception. The self includes the body (its image and evaluation), knowledge about the self (the structure of oneself), self-identity (what differentiates us from others), and the ability to make choices [12].

The purpose of this study is to evaluate both Quality of Life and Body Esteem scales by using laparoscopic and classical surgery treatment results as a basis for comparison. It also intends to determine if the QoL scale measures are the best available option for capturing distinct changes observed in the patients' perception of the results of laparoscopic and open surgery.

\section{Material and methods \\ Participants}

There were 57 participants from the General Surgery Department of Endocrinology and Transplantation at the Medical University of Gdansk. Thirty-five patients were operated on laparoscopically (25 cholecystectomies and 10 adrenalectomies), while 22 open surgery patients included 15 patients after cholecystectomy and 7 after adrenalectomy.

\section{Statistical analysis}

Two types of measuring tools were used: the Body Esteem Scale (BES) and Functional Assessment of Chronic Illness Therapy (FACIT). Both were distributed to the patients just before and 1 month after the operation. The Body Esteem Scale is a test which measures the level of satisfaction with one's body, initially proposed by Fanzoi et al. It consists of 36 items as different parts of the body scored by a patients on a 1 to 5 Likert scale (from not satisfied 
to very satisfied with it) [13]. BES is characterized by high reliability (0.81 to 0.87 ) [13].

Functional Assessment of Chronic Illness Therapy is a generic QoL measurement tool. In its core version it contains the following scales: physical state, emotional state, family and social life, and daily functioning. The scale is a 1 to 5 Likert scale with the answers: not at all, very little, a little, quite a lot, and very much [14-15]. The reliability of the scale is satisfactory to high (0.69 to 0.89) [15]. A Polish evaluation of the scale has been published previously by our team [16].

The statistical analysis was conducted using STATISTICA 9.0 PL licensed for use by the Medical University in Gdansk. The measurements of parametric variables included Student's $t$-test, and multidimensional measures were done using regression analysis. Differences were considered statistically significant at $p<0.05$.

\section{Results}

The analysis of the FACIT questionnaire results, conducted by the Student's t-test for independent variables, showed a lack of significant differences according to the quality of life evaluation among patients treated by either the laparoscopic or classical method, both before and after the operation. One month after the intervention, quality of life measures increased by $4.5 \%$ among patients after laparoscopy while those treated classically improved by $6.8 \%$. The differences were not significant either when compared to prior to the surgery or when cross-sectionally

Table I. Functional Assessment of Chronic Illness Therapy (FACIT)

\begin{tabular}{|lcc|}
\hline Operation & Before operation [\%] & After operation [\%] \\
\hline Laparoscopic & 64.3 & $67.8^{\star}$ \\
\hline Classic & 61.6 & $68.4^{\star}$ \\
\hline
\end{tabular}

${ }^{*} p<0.05$ in Student's t-test

Table II. Body Esteem Scale (BES)

\begin{tabular}{|c|c|c|}
\hline Operation & Before operation [\%] & After operation [\%] \\
\hline Laparoscopic & 56.7 & $53.8^{*}$ \\
\hline Classic & 56.6 & $28.1^{*}$ \\
\hline
\end{tabular}

comparing laparoscopic against open surgery (Table I). The results from the BES questionnaire analysis have shown that patients perceived their bodies as worse than before the operation in both cases. However, patients from the laparoscopic group were significantly more satisfied with their body image than those after the classic operation. Among patients after laparoscopic surgery the body image indicator decreased by $2.9 \%$ after the operation, while for patients after classic surgery it decreased by $28.5 \%$ (Table II).

The purpose of the logistic regression analysis was to determine which postoperative variable is more reliable in differentiating whether the patient was treated laparoscopically or with the open approach and therefore selecting a more sensitive variable for further presentation of changes observed between these 2 approaches. It was revealed that the quality of life 1 month after the operation was not a predictor of the method used during treatment (OR 1.01, 95\% Cl 0.75-1.35). In contrast, the values extracted from the BES post-operatively do indicate which patients were operated on videoscopically (OR 2.15, 95\% Cl 2.01-2.86).

\section{Discussion}

The present study confirmed that body image is a psychological measure which can be used to precisely evaluate the effects of laparoscopic and open surgery. The regression analysis indicated, through the minimal changes in value, that quality of life evaluation has its shortcomings as a determining measure or differentiator. Similarly, Persson et al. revealed that the quality of life measured by Psychological General Well Being (PGWB) did not differentiate 2 groups of gynaecological patients after laparoscopic and open hysterectomy [17]. This, however, does not mean that quality of life as a measurement is useless. In the research of Korolija et al. randomized trials indicated that quality of life improves earlier after endoscopic than open surgery for gastroesophageal reflux disease (GERD), cholecystolithiasis, colorectal cancer, inguinal hernia, obesity (gastric bypass), and uterine disorders that require hysterectomy [18]. This measure should be assessed in each individual patient case, despite the assumption that it is unchangeable. The results of quantitative research confirm such global meaning. The quality of life did not change substantially as a result of medical 
treatment, nor did it clearly identify the surgical approaches taken, while the BES clearly and definitively differentiated the approaches with its significant statistical data.

The surgical literature reports a number of examples of using body esteem as a worthwhile evaluation of the treatment method. In the study by Bemelman et al., the body esteem scale was used to compare the results of Crohn's disease treatment in which both laparoscopic and open methods were used. The authors revealed that the evaluation of the cosmetic effect of surgery is better among laparoscopic groups than classic groups, the difference being statistically significant $(p<0.001)$. There was a strong correlation between the quality of life index and the cosmetic effect after surgical treatment [19].

In research by Frederick et al. [20] on interest in cosmetic surgery and body image, the authors revealed that individuals interested in liposuction tended to have poorer body image and interest than amongst heavier individuals. This suggests that individuals interested in different types of cosmetic surgery may differ from each other in such attributes as body mass index and body image.

Another study concerning body image and quality of life in abdominoplasty patients was conducted by Bolton et al. [21]. It revealed significant positive post-surgical changes on the Appearance Evaluation subscale of the Multidimensional Body - Self Relations Questionnaire. The mean score for the questionnaire's Body Areas Satisfaction Scale improved postoperatively $(p<0.001)$. The score for the Body Exposure and Sexual Relations Questionnaire also improved significantly $(p<0.001)$ after the procedure. The above results indicate substantial improvements in body image which include positive changes in the patients' evaluations of their general appearance as well as their experiences of self-consciousness and avoidance of body exposure during sexual activities. No changes in general psychosocial functioning such as self-esteem, satisfaction with life, or social anxiety were seen. In another study, Madan et al. revealed that body esteem improves significantly after bariatric surgery [22]. The Body Esteem Scale for Adolescents and Adults (BESAA) was used in that study.

As for the results of the FACIT questionnaire there are no connections between the quality of life evaluation and the operational method. It should be considered that there are many common mistakes when determining the importance of quality of life. Caution should be taken when interpreting the results. Quality of life involves many factors that are not directly connected with the surgical intervention. Some possible aspects that can affect a patient's sense of well being are self-esteem, social support network, involvement in satisfactory relationships, social position, financial status, and uncontrollable life events.

In a study of Velanovich et al. [6] assessing the quality of life of patients undergoing 4 different types of laparoscopic and open operations - elective inguinal hernioplasty, oesophageal surgery, cholecystectomy, and splenectomy - patients completed the SF-36, a quality of life instrument. Typically for most contemporary QoL instruments, it measures physical functioning (PF), role-physical (RP), role-emotional $(\mathrm{RE})$, bodily pain (BP), vitality (VT), mental health $(\mathrm{MH})$, social functioning (SF), and general health $(\mathrm{GH})$ health status domains. The conclusion of the research was that laparoscopic surgery has demonstrably better early quality of life outcomes than open surgery for cholecystectomy, splenectomy, and oesophageal surgery. However, open hernioplasty has at least as good, if not better, health status outcomes than laparoscopic repair.

Topcu et al. [23] study aimed to compare the effects of 2 cholecystectomy techniques, laparoscopic vs. classic, on the quality of life and clinical outcome of the patients during long-term follow-up evaluation using SF-36. In addition to this, a system-specific instrument for gastrointestinal diseases was used to investigate the clinical outcome. The gastrointestinal clinical symptoms were similar in the 2 groups during the long-term follow-up evaluation, but laparoscopic cholecystectomy was found to be significantly superior to the open technique with respect to all aspects of quality of life over the long term. Despite apparently obvious results, this study caught the critical attention of our team [24]. The doubts concentrated on the improvement of quality of life and each of its dimensions, as well as maintaining this improvement during such a long postoperative period of 2 years. After detailed analysis, the researchers concluded that the experimental groups were significantly different. At the very beginning of the research the laparoscopic group patients paid for the treatment, whereas the classic operation group was treated under the health insurance. The researchers did not manage to avoid a few other mistakes: they did not reveal the quality of life measures at the beginning of the study (before the operation), and they did not control for the deter- 
minants of quality of life measures in the follow-up period. They also did not evaluate other medical and non-medical dimensions that could reflect the patients' status in the post-operational period. These kinds of methodological difficulties are not rare in surgical studies.

Despite the relatively clear results of the current study, the authors are aware of some important biases that might have influenced the results of the research. First, both groups were relatively small, and thus logistic regression analysis could not benefit from the group size. Second, the follow-up period was short. Though the results confirmed the primary hypotheses, we believe that the differences would be even more significant in longer follow-up. Such a study is currently ongoing. Third, as mentioned in the criticism to the study by Topcu et al., the longer the follow-up, the more careful the evaluation of concomitant psychological factors should be. With longer observations, the patients are susceptible to other life events that may influence quality of life and then blur the influence of the initial factor which is surgery and its mode.

Interesting aspects of body image evaluation have been presented by Kantoch et al. [25]. The authors revealed that scars resulting from heart surgery may have a considerable effect on a patient's body image and several other aspects of daily life in an attempt to determine the areas of life affected by surgical chest scarring. Out of 100 consecutive patients attending the clinic, $60 \%$ reported that the scar affected them less now than compared to their adolescence. The body was perceived as disfigured by $58 \%$ and the scar was concealed by $48 \%$ of the patients. Attention to the scar made $19 \%$ of the patients feel negative, $58 \%$ neutral, and $23 \%$ positive. Chest scarring was associated with decreased selfesteem in 20\% and decreased self-confidence in 18\% of the group. Patients reported less effect of chest scarring on their choice of career, success in life, friendships, sexual relationships, and choice of recreation. Also, $61 \%$ reported a positive effect on appreciation of health [25].

\section{Conclusions}

It can be concluded that body image evaluation may provide a more sensitive measure of differences experienced by patients treated by laparoscopic and classic surgery. Such small differences are especially visible in patients suffering from diseases that do not have a severe impact on quality of life. In such cases quality of life measures may not be sufficiently sensitive to differentiate between them, while body esteem may provide the answer to the question of what the patients really achieve through the minimally invasive approach.

\section{References}

1. Pozowski J, Poręba R, Buchacz P, Wiculska D. Chirurgia laparoskopowa w diagnostyce i leczeniu guzów przydatków. Ginekologia Praktyczna 2003; 11: 12-6.

2. Cuschieri A. Laparoscopic surgery: current status, issues and future developments. Surgeon 2005; 3: 125-38;

3. Budziński R, Michalik M, Frask, A. Edukacja w chirurgii laparoskopowej. Videosurgery and other miniinvasive techniques2008; 3: 22-9.

4. Buunen M, Gholghesaei R, Veldkamp R. Stress response to laparoscopic surgery. Surg Endosc 2004; 18: 1022-8.

5. Ueda K, Turner P, Gagner M. Stress response to laparoscopic liver resection. HPB (Oxford) 2004; 6: 247-52.

6 . Velanovich $\mathrm{V}$. Laparoscopic versus open surgery: a preliminary comparison of quality-of-life outcomes. Surg Endosc 2000; 14: $16-21$.

7. Dadan J, Iwacewicz P, Razak Hady H. Quality of life evaluation after selected bariatric procedures using the Bariatric Analysis and Reporting Outcome System. Videosurgery and other miniinvasive techniques 2010; 5: 93-9.

8. Dadan J, Iwacewicz P, Hady RH. Nowe trendy w chirurgii bariatrycznej. Videosurgery and other miniinvasive techniques 2008; 3: 66-70.

9. Kaska Ł, Śledziński Z, Kobiela J, et al. Porównanie jakości życia po operacjach laparoskopowych i klasycznych. Videosurgery and other miniinvasive techniques 2006; 2: 77-86.

10. Fleshman JW, Nelson H, Peters WR, et al. Early results of laparoscopic surgery for colorectal cancer. Retrospective analysis of 372 patients treated by Clinical Outcomes of Surgical Therapy (COST) Study Group. Dis Colon Rectum 1996; 39 (10 Suppl.): 53-8.

11. Keus F, de Jong JA, Gooszen HG, van Laarhoven CJ. Laparoscopic versus open cholecystectomy for patients with symptomatic cholecystolithiasis. Cochrane Database Syst Rev 2006; 18: CD006231.

12. Anderson N. Foundations of Information Integration Theory. Boston: Academic Press 1981.

13. Franzoi SL, Herzog M. The Body Esteem Scale: a convergent and Discriminant Validity Study. J Pers 1986; 50: 24-31.

14. Ward WL, Hahn EA, Mo F, et al. Reliability and validity of the Functional Assessment of Cancer Therapy-Colorectal (FACT-C) quality of life instrument. Qual Life Res 1999; 8: 181-95.

15. Webster K, Cella D, Yost K. The Functional Assessment of Chronic Illness Therapy (FACIT) Measurement System: properties, applications, and interpretation. Health Qual Life Outcomes 2003; 16: 79 .

16. Stefaniak T, Makarewicz W, Kossakowska M, et al. Application of the FACIT questionnaire in the evaluation of the quality of life in 
patients with chronic pancreatitis in Polish conditions. Pol Przegl Chir 2003; 75: 956-65.

17. Persson P, Wijma K, Hammar M, Kjølhede P. Psychological wellbeing after laparoscopic and abdominal hysterectomy-a randomized controlled multicentre study. BJOG 2006; 113: 1023-30.

18. Korolija D, Sauerland S, Wood-Dauphinee S, et al. Evaluation of quality of life after laparoscopic surgery - evidence-based guidelines of the EAES. Surg Endosc 2004; 18: 879-97.

19. Eshuis EJ, Polle SW, Slors JF, et al. Long-term surgical recurrence, morbidity, quality of life, and body image of laparoscopic-assisted versus open ileocolic resection for Crohn's disease: a comparative study. Dis Col Rectum 2008; 51: 858-67.

20. Frederick DA. Interest in cosmetic surgery and body image: views of men and women across the lifespan. Plast Reconstr Surg 2007; 120: 1407-15.

21. Bolton MA. Measuring outcomes in plastic surgery: body image and quality of life in abdominoplasty patients. Plast Reconstr Surg 2003; 112: 619-25.

22. Madan AK. Body esteem improves after bariatric surgery. Surg Innov 2008; 15: 32-7.

23. Topcu O, Karakayali F, Kuzu MA, et al. Comparison of long-term quality of life after laparoscopic and open cholecystectomy. Surg Endosc 2003; 17: 291-5.

24. Stefaniak T, Łachinski A, Vingerhoets A, Markuszewska-Proczko M. Long-term quality-of-life assessment after laparoscopic and classic cholecystectomy. Surg Endosc 2004; 18: 1152-3.

25. Kańtoch MJ, Eustace J, Collins-Nakai RL, et al. Znaczenie blizn po operacjach kardiochirurgicznych $u$ dorostych chorych operowanych w przeszłości z powodu wrodzonych wad serca. Kardiol Pol 2006; 64: 51-6. 